\title{
How to confuse a moral compass
}

\section{Survey 'magic trick' causes attitude reversal.}

\section{Zoë Corbyn}

19 September 2012

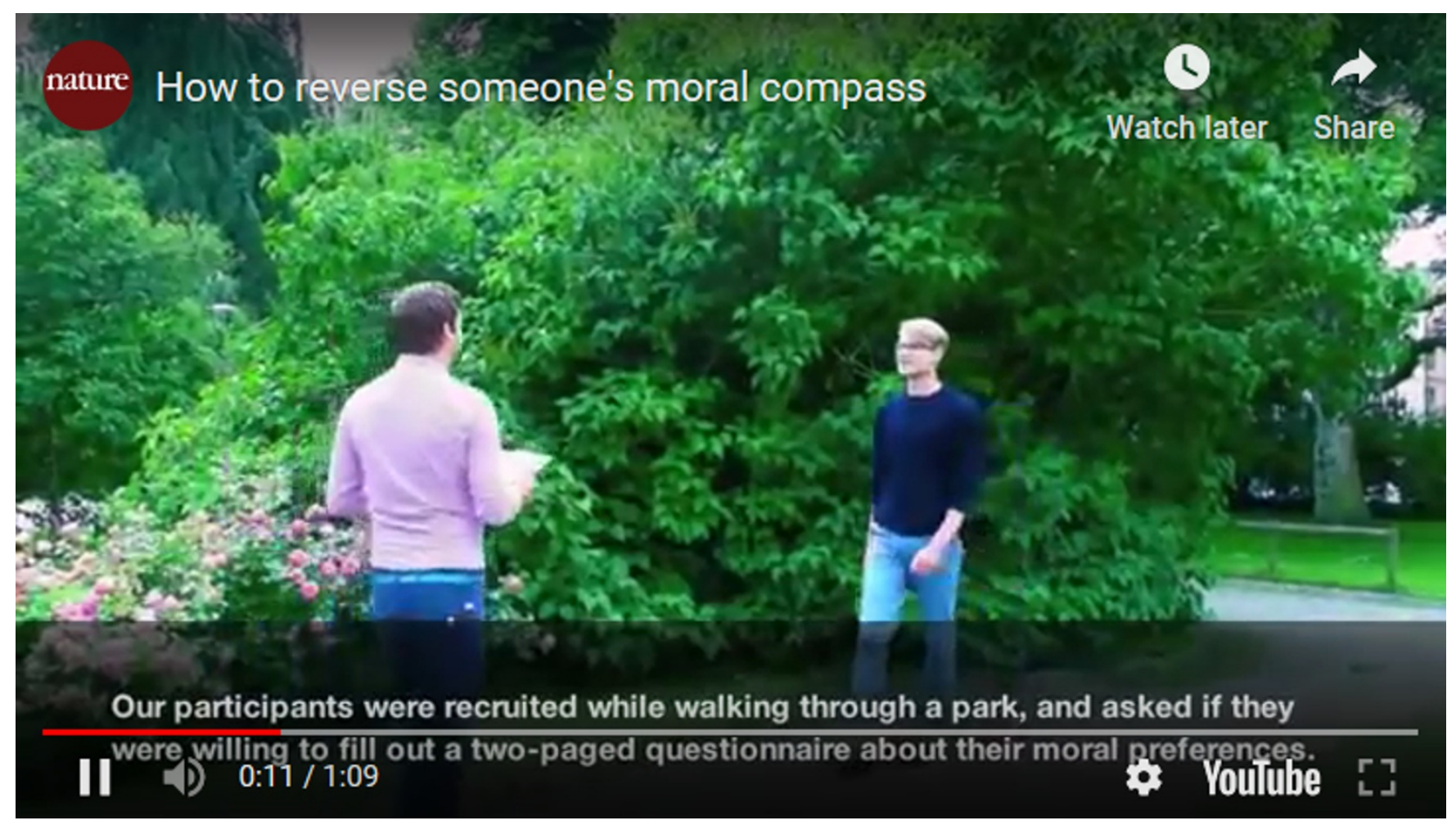

People can be tricked into reversing their opinions on moral issues, even to the point of constructing good arguments to support the opposite of their original positions, researchers report today in PLOS ONE ${ }^{1}$.

The researchers, led by Lars Hall, a cognitive scientist at Lund University in Sweden, recruited 160 volunteers to fill out a 2-page survey on the extent to which they agreed with 12 statements - either about moral principles relating to society in general or about the morality of current issues in the news, from prostitution to the Israeli-Palestinian conflict.

But the surveys also contained a 'magic trick'. Each contained two sets of statements, one lightly glued on top of the other. Each survey was given on a clipboard, on the back of which the researchers had added a patch of glue. When participants turned the first page over to complete the second, the top set of statements would stick to the glue, exposing the hidden set but leaving the responses unchanged.

Two statements in every hidden set had been reworded to mean the opposite of the original statements. For example, if the top statement read, "Large-scale governmental surveillance of e-mail and Internet traffic ought to be forbidden as a means to combat international crime and terrorism," the word 'forbidden' was replaced with 'permitted' in the hidden statement.

Participants were then asked to read aloud three of the statements, including the two that had been altered, and discuss their responses.

About half of the participants did not detect the changes, and $69 \%$ accepted at least one of the altered statements.

People were even willing to argue in favour of the reversed statements: A full $53 \%$ of participants argued unequivocally for the opposite of their original attitude in at least one of the manipulated statements, the authors write. Hall and his colleagues have previously reported this effect, called 'choice blindness', in other areas, including taste and smell ${ }^{2}$ and aesthetic choice ${ }^{3}$. 
"I don't feel we have exposed people or fooled them," says Hall. "Rather this shows something otherwise very difficult to show, [which is] how open and flexible people can actually be."

The study raises questions about the validity of self-report questionnaires, says Hall. The results suggest that standard surveys "are not good at capturing the complexity of the attitudes people actually hold", he says, adding that the switching technique could be used to improve opinion surveys in the future.

Tania Lombrozo, a psychologist at the University of California, Berkeley, says that the experiment is "creative and careful", but adds that it would be good to see the findings replicated with a more diverse group of participants and a broader range of claims, including those more likely to play a role in people's everyday judgement and behaviour. "For example, would people fail to notice a change in their judgement concerning the ethics of meat consumption and subsequently provide a justification for a view that isn't their own?" she asks.

The possibility of using the technique as a means of moral persuasion is "intriguing", says Liane Young, a psychologist at Boston College in Massachusetts. "These findings suggest that if I'm fooled into thinking that I endorse a view, l'll do the work myself to come up with my own reasons [for endorsing it]," she says.

Nature I doi:10.1038/nature.2012.11447

\section{References}

1. Hall, L., Johansson, P. \& Strandberg, T. PLoS ONE 7, e45457 (2012).

2. Hall, L., Johansson, P., Tärning, B., Sikström, S. \& Deutgen, T. Cognition 117, 54-61 (2010).

3. Johansson, P., Hall, L., Sikström, S. \& Olsson, A. Science 310, 116-119 (2005). 